\title{
Characterisation of metabolites of the putative cancer chemopreventive agent quercetin and their effect on cyclo-oxygenase activity
}

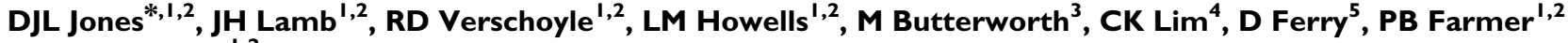 \\ and AJ Gescher ${ }^{1,2}$
}

'Cancer Biomarkers and Prevention Group, Department of Biochemistry, Biocentre, University of Leicester, Leicester LEI 7RH, UK; ${ }^{2}$ Cancer Biomarkers and Prevention Group, Department of Cancer Studies, University of Leicester, Leicester LEI 7RH, UK; ${ }^{3}$ Medical Research Council Toxicology Unit, University of Leicester, Leicester LEI 9HN, UK; ${ }^{4}$ Medical Research Council Bioanalytical Science Group, School of Biological and Chemical Sciences, Birkbeck College, University of London, Malet Street, London WCIE 7HX, UK; ${ }^{5}$ The Royal Wolverhampton Hospitals NHS Trust, New Cross Hospital, Wednesfield Road, Wolverhampton WVIO OQP, UK

\begin{abstract}
Quercetin (3,5,7,3',4'-pentahydroxyflavone) is a flavone with putative ability to prevent cancer and cardiovascular diseases. Its metabolism was evaluated in rats and human. Rats received quercetin via the intravenous (i.v.) route and metabolites were isolated from the plasma, urine and bile. Analysis was by high-performance liquid chromatography and confirmation of species identity was achieved by mass spectrometry. Quercetin and isorhamnetin, the 3'-O-methyl analogue, were found in both the plasma and urine. In addition, several polar peaks were characterised as sulphated and glucuronidated conjugates of quercetin and isorhamnetin. Extension of the metabolism studies to a cancer patient who had received quercetin as an i.v. bolus showed that (Quercetin removed) isorhamnetin and quercetin 3'-O-sulphate were major plasma metabolites. As a catechol, quercetin can potentially be converted to a quinone and subsequently conjugated with glutathione (GSH). Oxidation of quercetin with mushroom tyrosinase in the presence of GSH furnished GSH conjugates of quercetin, two mono- and one bis-substituted conjugates. However, these species were not found in biomatrices in rats treated with quercetin. As cyclo-oxygenase-2 (COX-2) expression is mechanistically linked to carcinogenesis, we examined whether quercetin and its metabolites can inhibit COX-2 in a human colorectal cancer cell line (HCA-7). Isorhamnetin and its $4^{\prime}$-isomer tamarixetin were potent inhibitors, reflected in a $90 \%$ decrease in prostaglandin E-2 (PGE-2) levels, a marker of COX-2 activity. Quercetin was less effective, with a 50\% decline. Quercetin 3- and 7-O-sulphate had no effect on PGE-2. The results indicate that quercetin may exert its pharmacological effects, at least in part, via its metabolites.
\end{abstract}

British Journal of Cancer (2004) 91, 1213-1219. doi:I0.1038/sj.bjc.6602091 www.bjcancer.com

Published online 3 August 2004

(c) 2004 Cancer Research UK

Keywords: cancer chemoprevention; cyclo-oxygenase; metabolism; quercetin

Naturally occurring flavonoids in the diet are associated with several beneficial health effects and understanding the mechanisms underlying these effects has become the focus of much research. Quercetin $\left(3,5,7,3^{\prime}, 4^{\prime}\right.$-pentahydroxyflavone, for structure see Figure 1) is a prime example of such a flavonoid. Its glycosylated form occurs in kale, French beans, broccoli, apples and especially in onions, with an abundance as high as a quarter to half a gram per kg (Hertog et al, 1992). On ingestion with the diet, quercetin glycosides are rapidly hydrolysed to generate quercetin.

Epidemiological evidence links diets rich in quercetin with decreased incidence of cardiovascular and neoplastic diseases (Hertog et al, 1993, 1994, 1995; Hertog and Hollman, 1996; Keli et al, 1996; Le Marchand et al, 2000). From the mechanistic standpoint, quercetin has been shown to interact with cellular processes in numerous ways (for a review see Nijveldt et al, 2001).

*Correspondence: Dr DJL Jones; E-mail: djjj @@le.ac.uk

Received I5 March 2004; revised 28 June 2004; accepted 29 June 2004; published online 3 August 2004
Recently, cyclo-oxygenase (COX) enzymes, especially COX-2, have been causally implicated in the early changes associated with carcinogenesis in a number of tissues, among which the colorectal tract has been studied most extensively (Marnett and Dubois, 2002). A noteworthy mechanistic facet of quercetin is its ability to interfere with COX by inhibiting COX-2 promoter activity (Mutoh et al, 2000), COX-2 protein expression (Raso et al, 2001) and COX enzyme activity (Formica and Regelson, 1995). In the light of its interesting biological properties germane to anticarcinogenesis, quercetin has been subjected to a phase I clinical trial in cancer patients, with the aim to develop it as a cancer chemopreventive or antineoplastic agent (Ferry et al, 1996). With respect to potential detrimental effects on health by quercetin, it has been suggested to possess mutagenic and carcinogenic properties (MacGregor and Jurd, 1978; Dunnick and Hailey, 1992), and at high doses there were indications of toxicity in humans (Ferry et al, 1996).

Quercetin shares with many naturally occurring polyhydroxylated molecules poor bioavailability (Hollman and Katan, 1997), which is probably a consequence of its rapid metabolic transformation in the liver and gastrointestinal tract. Evidence is 
Quercetin $\mathrm{R}_{1}=\mathrm{H}$ \& $\mathrm{R}_{2}=\mathrm{H}$<smiles>CCCOc1cc(-c2oc3cc(O)cc(O)c3c(=O)c2O)ccc1O</smiles>

Isorhamnetin $\mathrm{R}_{1}=\mathrm{CH}_{3} \& \mathrm{R}_{2}=\mathrm{H}$

Tamarixetin $\mathrm{R}_{1}=\mathrm{H} \& \mathrm{R}_{2}=\mathrm{CH}$

Figure I Structures of quercetin and its metabolites.

accumulating that metabolites of dietary polyphenols may mediate, or substantially contribute to, the pharmacological efficacy of the parent molecule, and thus explain efficacy despite the apparent low bioavailability, as is observed with $1,3,4^{\prime}$ trihydroxy-trans-stilbene (resveratrol), which is found in grapes (Gescher and Steward, 2003). Therefore, identifying the metabolites of dietary components such as quercetin and resveratrol and defining their contribution to the pharmacological and biological effects of the parent molecule is of great importance. The fate in the mammalian organism of the dietary progenitor glycosides of quercetin, such as rutin and quercetrin, has been more extensively studied than the metabolism of quercetin itself, when administered in aglyconic form. Quercetin is oxidatively degraded to nonflavone phenols, probably by intestinal bacteria (Booth et al, 1956; Douglass and Hogan, 1958; Petrakis et al, 1959). Moreover, these fission products have been shown to possess biological activity (Merfort et al, 1996). Most importantly, quercetin has been shown to undergo conjugation with glucuronide and sulphate at one or more of the five hydroxyl moieties of the flavone molecule and methylation at positions $3^{\prime}$ or $4^{\prime}$, thus generating isorhamnetin $\left(3^{\prime}\right.$ $O$-methylquercetin) and tamarixetin (4'-O-methylquercetin). These conjugates have been characterised in rat urine, bile and plasma (Ueno et al, 1983; Manach et al, 1997; Piskula and Terao, 1998). A quercetin sulphate and two quercetin sulphate-glucuronides were also found in the perfused rat liver (Shali et al, 1991). Metabolites were also identified in human plasma following the ingestion of a complex meal rich in plant products (Manach et al, 1998, Day et al, 2001). Two pharmacokinetic studies of authentic quercetin in humans established that it is rapidly cleared from the organism (Gugler et al, 1975; Ferry et al, 1996).

In the light of the interest in quercetin as a potential cancer chemopreventive or chemotherapeutic agent, we reinvestigated its metabolism in the rat using mass spectrometric methods of chemical identification. A particular aim of the study was to compare the qualitative pattern observed in rat plasma with that found in a human who had undergone treatment with quercetin in a clinical trial (Ferry et al, 1996). In the light of the indications of its potential nephrotoxicity demonstrated in that trial, we tested the potential of quercetin to undergo biotransformation via conjugation with glutathione (GSH) to a proximate nephrotoxicant, analogous to the nephrotoxicity associated with hydroquinone (Peters et al, 1997), bromohydroquinone (Monks et al, 1985), 17 $\beta$-estradiol (Butterworth et al, 1997) or haloalkenes (Iverson et al, 1996). Previous reports have indicated that GSH conjugates are formed in vitro (Awad et al, 2000, 2001; Boersma et al, 2000; Galati et al, 2001). Furthermore, mindful of the fact that COX activity is a potential mechanistic target of quercetin, we compared its effect on cellular prostaglandin E-2 (PGE-2) production with that of representative quercetin metabolites. Overall the work was designed to contribute to the database required for the optimisation of the clinical development of quercetin as a potential cancer chemopreventive and/or chemotherapeutic agent.

\section{MATERIALS AND METHODS}

\section{Materials}

The following materials were purchased from the indicated sources. Quercetin, rutin mushroom tyrosinase, high-performance liquid chromatography (HPLC) grade dimethyl sulphoxide (DMSO), ammonium acetate: Sigma (Poole, UK); HPLC grade methanol: Fisher (Loughborough, UK); isorhamnetin, tamarixetin, quercetin 3-O-sulphate: Extrasynthese (Genay, France); and glycerol formal: Fluka (Poole, UK). Human colon adenoma cells (HCA-7, passage number 29) were obtained from Dr S Kirkland (Imperial College, London, UK).

\section{Animals, treatments and incubation conditions}

Male F344 rats (200-250 g) were used. For metabolite analysis in the plasma, animals were anaesthetised with pentobarbital $(6 \mathrm{mg}$ per rat, i.p.), and quercetin $\left(6.25 \mathrm{mg} \mathrm{kg}^{-1}\right)$ dissolved in glycerol formal and water $1: 1$ was injected intravenous (i.v.) via the lateral tail vein (injection volume: $100 \mu \mathrm{l}$ ). After $5 \mathrm{~min}$ blood was collected by cardiac puncture. For the analysis of metabolites in bile, the quercetin dose was $12.5 \mathrm{mg} \mathrm{kg}^{-1}$ (i.v.). For the study of urinary metabolites, quercetin dissolved in DMSO $\left(0.5 \mathrm{ml} \mathrm{kg}^{-1}\right)$ was given by gavage $\left(2.5 \mathrm{~g} \mathrm{~kg}^{-1}\right)$, rats were transferred to metabolism cages and urine was collected for up to $24 \mathrm{~h}$ postadministration. For the analysis of metabolites in the bile, rats were anaesthetised (pentobarbitol) and the bile duct was cannulated. Ambient body temperature was maintained using a heat lamp. Control animals received the vehicle only. Experiments were conducted as stipulated by Project Licence $80 / 1250$ granted by the UK Home Office. The experimental design was vetted and approved by the Leicester University Ethical Committee for Animal Experimentation and meet the standards required by the UKCCCR guidelines (Workman et al, 1998).

In order to generate reactive oxidation products of quercetin in vitro, quercetin and GSH (1 mM each) were incubated for $1 \mathrm{~h}$ $\left(37^{\circ} \mathrm{C}\right)$ with mushroom tyrosinase in ammonium acetate buffer (0.1 M, pH 7.4).

\section{Quercetin metabolism in a human}

Blood samples were obtained from a cancer patient, at the Queen Elizabeth Hospital (Birmingham, UK), who no longer responded to standard therapy and had been recruited into a phase I clinical study of quercetin. This trial has been described in detail before (Ferry et al, 1996). Quercetin formulated in DMSO was infused i.v. $\left(250 \mathrm{mg} \mathrm{m}^{-2}\right.$ for $\left.5 \mathrm{~min}\right)$ and blood was obtained up to $2 \mathrm{~h}$ postadministration. The plasma was separated and stored at $-80^{\circ} \mathrm{C}$.

\section{Sample preparation and HPLC analysis}

Aliquots of plasma, urine, bile or tyrosinase incubate were mixed with twice the volume of DMSO/methanol $\left(1: 4, \mathrm{vv}^{-1}\right)$. Kaempferol (internal standard) was added and the mixture was vortexed and centrifuged $(17060 \mathrm{~g}, 15 \mathrm{~min})$. The supernatant was removed, diluted with water $(1: 1)$ and injected onto the HPLC column (injection volume $50 \mu \mathrm{l}$ ). Hydrolysis of glucuronide and sulphate conjugates of quercetin in the plasma or bile was performed as described by Ader et al (2000). In short, $\beta$-glucuronidase solution (500 $\mathrm{U}$ in $0.1 \mathrm{M}$ ammonium acetate $\mathrm{pH} 6.8$ ) also containing sulphatase was added to an aliquot $(0.1 \mathrm{ml})$ of biofluid (acidified with $20 \mu \mathrm{l}$ of $0.5 \mathrm{M}$ acetic acid). Incubations were carried out for $30 \mathrm{~min}$ at $37^{\circ} \mathrm{C}$, which furnished maximal deconjugation. Following incubation samples were extracted for analysis.

High-performance liquid chromatography analysis was performed on a Varian Prostar system, which comprised of a UV 


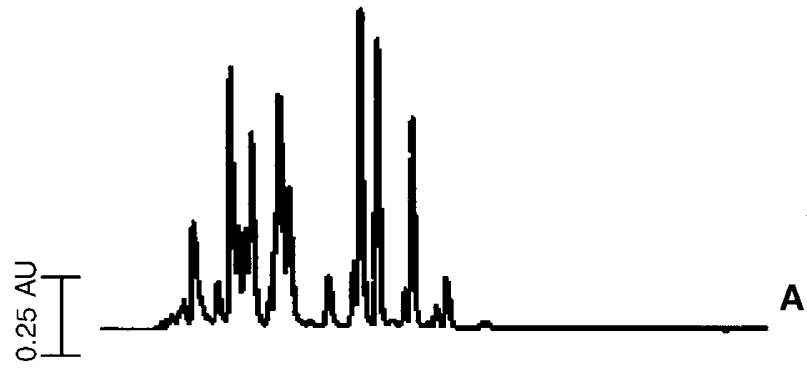

B
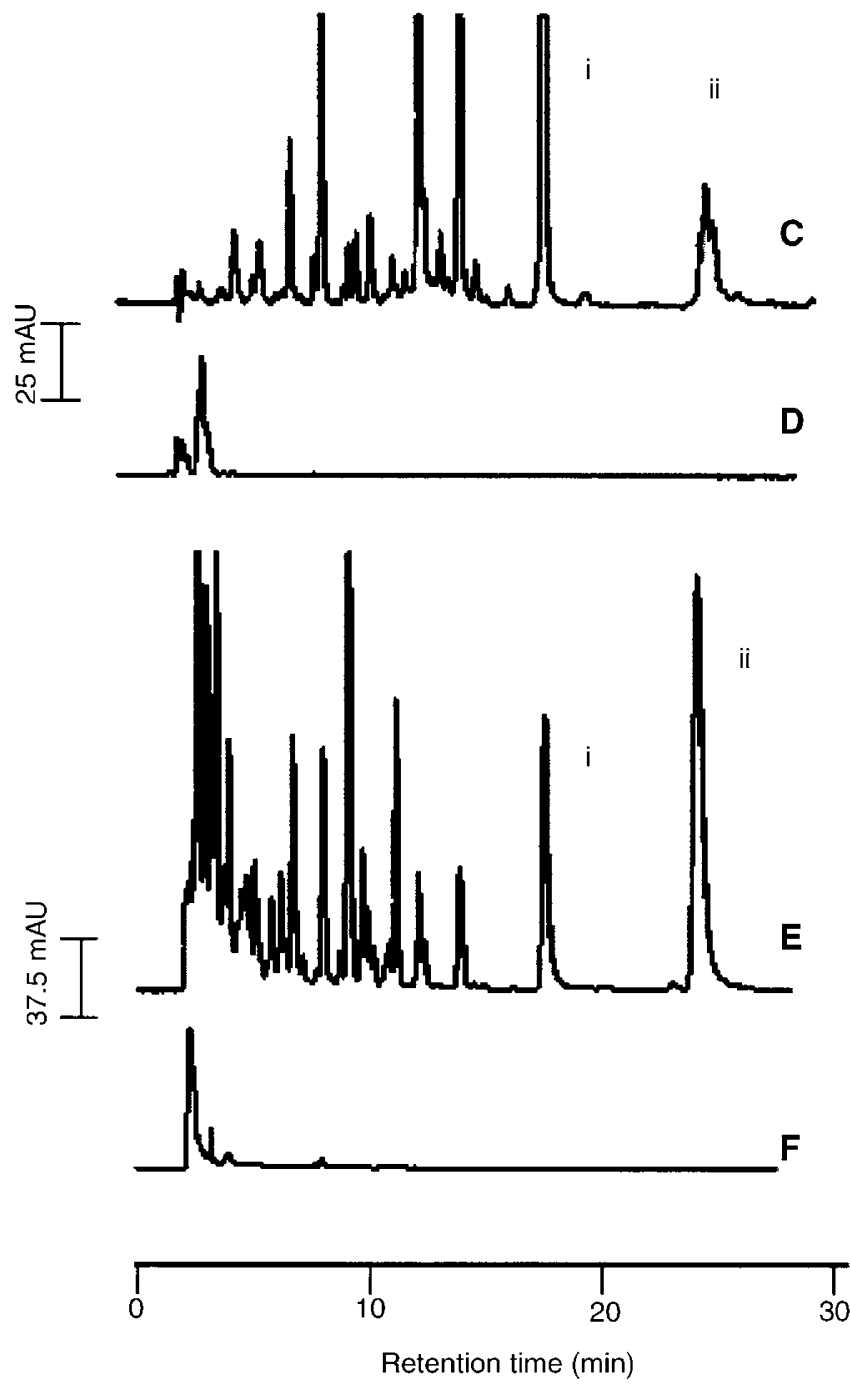

Figure 2 High-performance liquid chromatography chromatograms of extracts of bile $(\mathbf{A}$ and $\mathbf{B})$, plasma $(\mathbf{C}$ and $\mathbf{D})$ or urine $(\mathbf{E}$ and $\mathbf{F})$ from control rats $(\mathbf{B}, \mathbf{D}$ and $\mathbf{F})$ or rats that had received quercetin either 12.5 (A) or $6.25 \mathrm{mg} \mathrm{kg}^{-1}$ (C) and $2.5 \mathrm{~g} \mathrm{~kg}^{-1}(\mathbf{E})$ via the i.v. (A and $\mathbf{C}$ ) or oral (E) routes. Bile was collected prior to (control) and for 20 min after the administration of quercetin; plasma samples were collected 5 min after administration of quercetin; urine samples were pooled over $8 \mathrm{~h}$. Control (untreated) animals received the vehicle only via the appropriate administration route. Symbols $i$ and ii denote retention times of quercetin and isorhamnetin, respectively. $\mathrm{AU}=$ absorbance units. For details of sample preparation and chromatographic analysis see Materials and Methods. The chromatograms shown are representative of extracts obtained from three separate animals. detector (model 310), solvent delivery system (model 230) and an autosampler (model 410) with a $100 \mu \mathrm{l}$ loop. Detection was by UV at $375 \mathrm{~nm}$. Analysis of the human plasma samples was performed as described previously (Jones et al, 1998). Analysis of extracts of rat plasma, urine or bile involved a gradient mobile phase system (75\% $0.1 \mathrm{M}$ ammonium acetate in methanol, decreased linearly to $55 \%$ for $10 \mathrm{~min}$ and to $45 \%$ for a further $20 \mathrm{~min}$, at which it remained for a further $5 \mathrm{~min}$ ). The flow rate was $1 \mathrm{ml} \mathrm{min}^{-1}$. Separation was achieved on a Hypersil BDS $\mathrm{C}_{18}$ column $\left(250 \times 4.6 \mathrm{~mm}^{2}\right.$ i.d., $5 \mu \mathrm{m}$ particle size; Hypersil, Runcorn, UK). The mobile phase used for the analysis of GSH conjugates consisted of the same start eluent, but the content of ammonium acetate decreased to $55 \%$ for $20 \mathrm{~min}$, at which it remained for a further $50 \mathrm{~min}$.

For the quantitation of quercetin in plasma stock solutions $\left(10 \mathrm{mg} \mathrm{ml}^{-1}\right)$ of quercetin and kaempferol (internal standard) were made up (DMSO), and the calibration curve was constructed with five concentrations of quercetin (final concentrations 1, 2, 20, 100 and $200 \mu \mathrm{g} \mathrm{ml}^{-1}$ ). The recovery of quercetin from the plasma was $90 \%$, and the concentrations described in the results were corrected correspondingly.

\section{Mass spectrometry (MS)}

A Quattro Bio-Q triple stage mass spectrometer (Micromass, Manchester, UK) fitted with pneumatically assisted electrospray (pnESI) was coupled to a Varian 9012 pump (flow rate: $\left.1 \mathrm{ml} \mathrm{min}{ }^{-1}\right)$. A tee-piece was incorporated postcolumn to give a $1: 7 \mathrm{split}$, so that approximately $140 \mu \mathrm{lmin}^{-1}$ entered the source region of the mass spectrometer. Standards were infused into the mass spectrometer using a Harvard syringe pump $\left(10 \mu \mathrm{l} \mathrm{min}^{-1}\right)$. Typically, a capillary voltage of $3.78 \mathrm{kV}$, HV lens voltage of $0.2 \mathrm{kV}$ and a cone voltage of $46 \mathrm{~V}$ was used. Source temperature was $110^{\circ} \mathrm{C}$. Two types of experiments were conducted: (i) a scan of $50-$ $1300 \mathrm{~m} / \mathrm{z}$, from which ion chromatograms were extracted postrun and (ii) LC-MS/MS in which specific ions underwent dissociation in the collision cell. Collision gas was argon. All mass spectra were acquired in the negative ion mode.

\section{PGE-2 levels in HCA-7 cells}

HCA-7 cells were routinely cultured in Dulbecco's MEM medium with Glutamax (Gibco, Invitrogen Corp., UK) supplemented with $10 \%$ foetal calf serum and penicillin/streptomycin (1000 and $500 \mathrm{U} \mathrm{ml}^{-1}$, respectively). Cells $\left(10^{5}\right.$ well $\left.^{-1}\right)$ were incubated for $6 \mathrm{~h}$ with quercetin $(1-75 \mu \mathrm{M})$ or quercetin metabolites $(10 \mu \mathrm{M})$ dissolved in DMSO. Control cultures contained DMSO only. An aliquot $(1 \mathrm{ml})$ of cellular supernatant was removed from each of the plates after $6 \mathrm{~h}$ and analysed in duplicate for PGE-2 content using a kit, which employs an ELISA immunoassay (Cayman Chemical Comp., MI, USA). Experiments were repeated three times. An initial experiment involved the incubation of $50 \mu \mathrm{M}$ quercetin and taking samples at both 6 and $24 \mathrm{~h}$.

\section{RESULTS}

\section{Metabolites of quercetin in the rat}

High-performance liquid chromatography analysis of plasma and urine samples from rats, which had received quercetin $\left(6.25 \mathrm{mg} \mathrm{kg}^{-1}\right)$ via the i.v. route, contained quercetin (retention time $17.5 \mathrm{~min}$, peak $\mathrm{i}$ in Figure 2) and a major metabolite (retention time $26 \mathrm{~min}$, peak ii in Figure 2), which coeluted with isorhamnetin. Peak identification was confirmed by both on-line LC-MS and LC-MS of collected peak fractions, furnishing deprotonated molecule ions of $\mathrm{m} / \mathrm{z} 301$ for quercetin and $\mathrm{m} / \mathrm{z}$ 315 for isorhamnetin. 
Extracts of plasma, urine or bile from quercetin-treated animals characteristically gave 15 to 18 extra peaks (between the retention times of 5 and $16 \mathrm{~min}$ ) that were absent from extracts of biomatrices obtained from untreated animals (Figure 2). On the basis of their polarity, these species were hypothesised to constitute sulphate and glucuronide conjugates of quercetin, which was confirmed by their disappearance on treatment with sulphatase and $\beta$-glucuronidase and a concomitant increase in the size of the quercetin and isorhamnetin peaks (result not shown). To confirm this conclusion, the extracts were analysed by LC-MS and ion chromatograms extracted postrun. Based on the pseudomolecular ion, 10 different types of conjugate species were detected (Table 1). In order to illustrate the findings in Table 1, Figure 3 shows an extracted ion chromatogram of $\mathrm{m} / \mathrm{z} 477$ of quercetin glucuronides found in the bile. Allocation of these structures to chromatographic peaks furnished the following number of positional isomers: two isomers each of quercetin

Table I Deprotonated molecular ions $[\mathrm{M}-\mathrm{H}]^{-}$and $\mathrm{HPLC}$ retention times of metabolites of quercetin identified by selected ion monitoring in the plasma, urine and bile of rats that received quercetin $\left(6.25 \mathrm{mg} \mathrm{kg}^{-1}\right.$ i.v. $)$

\begin{tabular}{|c|c|c|c|}
\hline Metabolite & $\mathbf{m} / \mathbf{z}$ & $\begin{array}{l}\text { Number of } \\
\text { isomers }\end{array}$ & Retention time (min) \\
\hline Quercetin glucuronides & 477 & 5 & $7.32,8.76,9.85,10.77,13.08$ \\
\hline Quercetin sulphates & 381 & 2 & $8.67,14.92$ \\
\hline Quercetin sulphate-glucuronides & 557 & 5 & $4.90,5.76,6.40,6.71,6.97$ \\
\hline Quercetin bis-sulphates & 461 & 2 & $11.52,12.30$ \\
\hline Quercetin bis-glucuronides & 653 & 2 & $5.01,5.45$ \\
\hline Isorhamnetin glucuronides & 491 & 4 & $10.08,10.72,12.16,13.48$ \\
\hline Isorhamnetin sulphates & 395 & 2 & $9.54,14.98$ \\
\hline Isorhamnetin bis-glucuronides & 667 & 2 & $4.61,5.30$ \\
\hline Isorhamnetin sulphate-glucuronide & 571 & 5 & $5.22,5.86,6.51,6.80,7.23$ \\
\hline Isorhamnetin bis-sulphate & 475 & 4 & $9.54,11.18,11.29,11.61$ \\
\hline
\end{tabular}

$\mathrm{HPLC}=$ high-performance liquid chromatography sulphate, quercetin bis-sulphate, quercetin bis-glucuronide, isorhamnetin sulphate and isorhamnetin bis-glucuronide, four isomers of isorhamnetin bis-sulphate, four isomers of isorhamnetin glucuronide, and five isomers each of quercetin sulphateglucuronide and isorhamnetin sulphate-glucuronide. Of the two isomeric quercetin sulphates found, the species characterised by a retention time of $8.7 \mathrm{~min}$ coeluted with authentic quercetin $3^{\prime}-O$ sulphate. Characterisation of urine extracts by LC-MS/MS led to the identification of six species, quercetin, isorhamnetin, quercetin sulphate, quercetin glucuronide, isorhamnetin glucuronide and quercetin bis-glucuronide (Table 2). Cochromatography suggested that the urinary quercetin sulphate was quercetin $3^{\prime}-O$-sulphate.

In an attempt to obtain preliminary information on quercetin levels, quercetin was quantitated in the plasma. Shortly after administration $(5 \mathrm{~min})$ quercetin levels in the plasma were $13.7 \pm 4.1 \mu \mathrm{M}(n=6)$, beyond which time the agent disappeared rapidly. Quercetin conjugates were present until the 90 min time point postadministration. When plasma samples were subjected to enzymatic hydrolysis, the level of total quercetin, that is, conjugated and unconjugated, at the $5 \mathrm{~min}$ time point increased to $76.9 \pm 11.4 \mu \mathrm{M}$. These results suggest that at this early time point species derived from quercetin circulating in the blood were predominantly quercetin glucuronides and sulphates. Bile obtained from these rats showed the presence of quercetin metabolites for up to $2 \mathrm{~h}$ postadministration.

\section{Metabolites of quercetin in human plasma}

A patient with confirmed cancer received quercetin via the i.v. route. Extracts of plasma obtained just prior to, and $5 \mathrm{~min}$ after, drug administration were analysed by HPLC (Figure 4) using an isocratic method, in contrast to the gradient elution procedure employed in the rat study described above. Analysis by MS of peak eluates confirmed the inferences for quercetin, isorhamnetin and quercetin $3^{\prime}$-O-sulphate $\left([\mathrm{M}-\mathrm{H}]^{-}=m / z 381\right)$. When plasma from

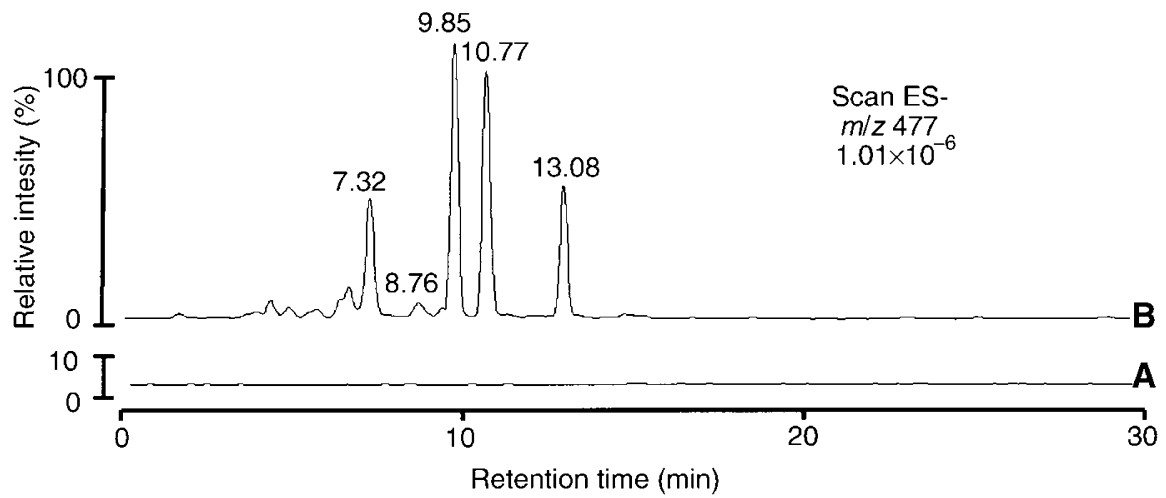

Figure 3 Extracted ion chromatogram $(\mathrm{m} / \mathrm{z} 477)$ of $(\mathbf{A})$ extract of bile from control rat and $(\mathbf{B})$ quercetin glucuronides from bile of rats, which received quercetin $\left(12.5 \mathrm{mg} \mathrm{kg}^{-1}\right.$ i.v.). Retention times are those noted in Table I.

Table 2 Mass spectral properties of quercetin and five quercetin metabolites in the urine

\begin{tabular}{lcl}
\hline Metabolite & Retention time $\mathbf{( m i n}^{\mathbf{a}}$ & $\mathbf{m} / \mathbf{z}$ (relative intensity) \\
\hline Quercetin & 19.2 & $301(50), 151(100), 273(15), 179(16), 135(30), 121(29), 107(50)$ \\
Isorhamnetin & 26.7 & $315(10), 300(90), 271(20), 151(100), 107(90)$ \\
Quercetin sulphate & 15.6 & $381(60), 301(100), 179(20), 151(50), 107(30)$ \\
Quercetin glucuronide & 9.3 & $477(15), 301(100), 179(12), 151(20)$ \\
Isorhamnetin glucuronide & 12.6 & $491(10), 315(50), 300(100), 271(10), 151(10)$ \\
Quercetin bis-glucuronide & 3.8 & $653(100), 477(20), 301(10), 151(10)$
\end{tabular}

${ }^{\mathrm{a}}$ Owing to the fact that this analysis was conducted over a considerable time after that shown in Table I, the retention times shown for the sulphates and glucuronides differ from those described in Table I by up to $0.8 \mathrm{~min}$. 


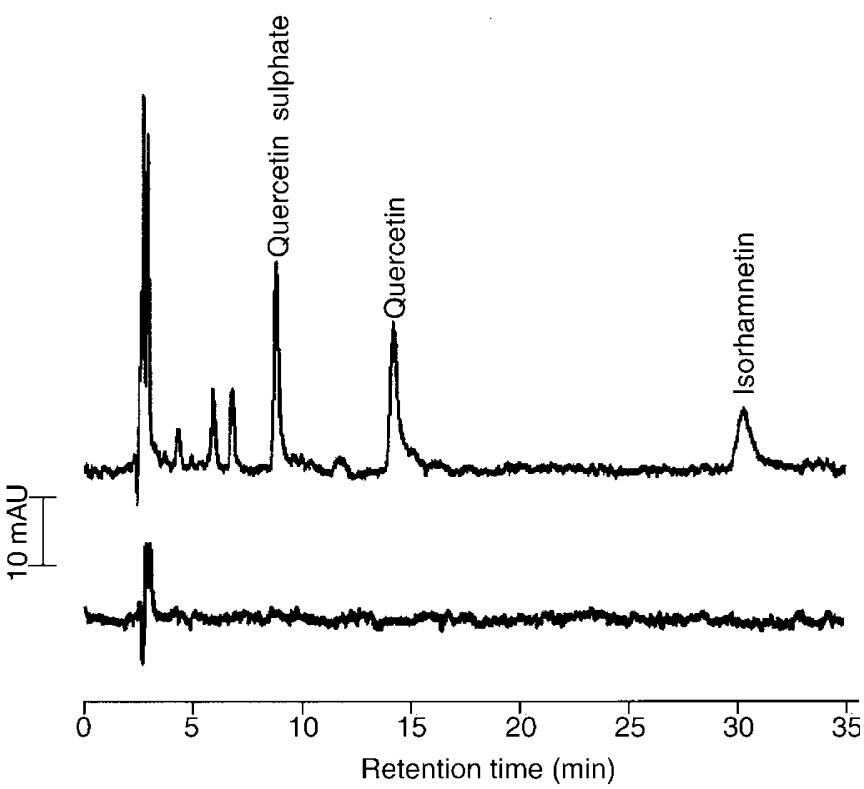

Figure 4 High-performance liquid chromatography chromatograms of extracts of plasma from a patient obtained before (bottom trace) and $5 \mathrm{~min}$ after administration (top trace) of quercetin $\left(280 \mathrm{mg} \mathrm{m}^{-2}\right.$ i.v.). Peaks were identified on the basis of cochromatography and selected ion monitoring MS, which afforded $\mathrm{m} / \mathrm{z} 30 \mathrm{I}$ for quercetin, $\mathrm{m} / \mathrm{z} 315$ for isorhamnetin and $\mathrm{m} / \mathrm{z} 38 \mathrm{I}$ for quercetin 3-O-sulphate. $\mathrm{AU}=$ absorbance units. For details of sample preparation and chromatographic and mass spectrometric analysis see Materials and Methods.

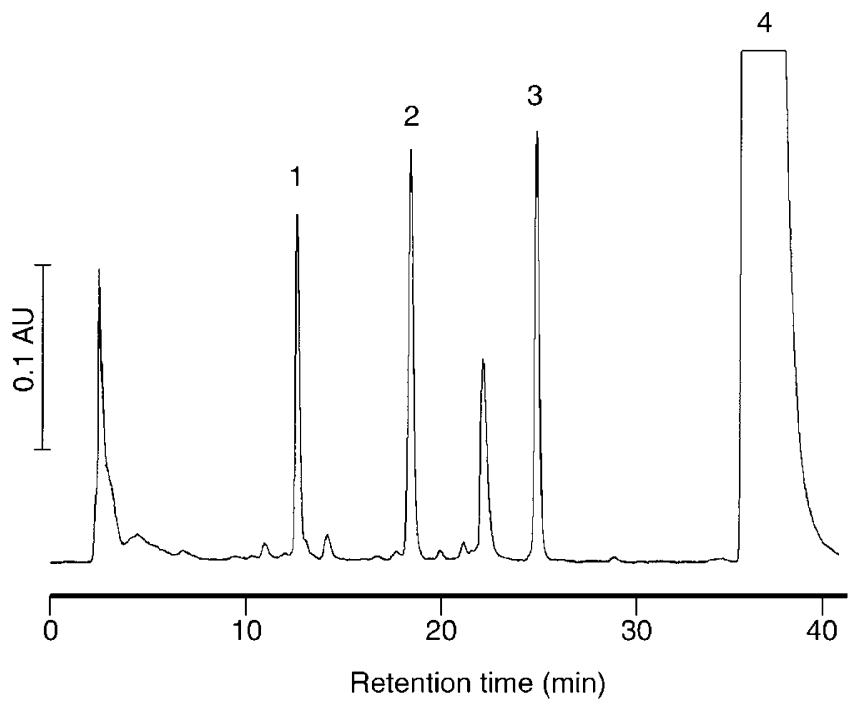

Figure 5 High-performance liquid chromatography chromatogram of an extract of a mixture of quercetin (I mM), glutathione (I mM) and mushroom tyrosinase $\left(150 \mathrm{Uml}^{-1}\right)$. Mass spectral analysis performed in the selected ion monitoring mode suggests the following peak allocation: 'I' bis-glutathionyl-S-quercetin ( $\mathrm{m} / \mathrm{z} 9 \mathrm{I})$ ), '2' and ' 3 ' glutathionyl-S-quercetin $(\mathrm{m} / \mathrm{z}$ 606) and ' 4 ' quercetin. $A U=$ absorbance units. For details of incubation conditions, sample preparation and chromatographic conditions see Materials and Methods. The chromatogram shown is representative of three separate experiments.

a rat, which had received quercetin, was analysed using the isocratic method, these three species were similarly prominent (data not shown).

\section{GSH conjugates of quercetin}

In the light of the nephrotoxic manifestations of quercetin observed in a clinical trial (Ferry et al, 1996), the hypothesis was tested such that quercetin might undergo metabolic oxidation in species reacting with GSH conjugation to furnish moieties that could potentially be targeted specifically to the kidney. To this end, quercetin was incubated with mushroom tyrosinase, which can oxidise catechols to their quinones (Duckworth and Coleman, 1970). High-performance liquid chromatography analysis of an extract of the reaction mixture furnished seven peaks eluting prior to quercetin (Figure 5). Off-line HPLC-MS analysis afforded $\mathrm{m} / \mathrm{z}$ $911[\mathrm{M}-\mathrm{H}]^{-}$for peak ' 1 ', consistent with bis-glutathionyl-Squercetin, while peaks ' 2 ' and ' 3 ' furnished $m / z 606[\mathrm{M}-\mathrm{H}]^{-}$, suggestive of glutathionyl-S-quercetin. Similar results were obtained when horseradish peroxidase was used as an oxidising agent instead of tyrosinase. Next, the hypothesis was tested such that GSH conjugates also occur in rats, which had received quercetin via the p.o. or i.v. routes. However, none of the species observed in the in vitro incubates (Figure 5) could be detected in extracts of plasma, urine, faeces or bile from rats. Additional experiments in which the catabolism of GSH conjugate species was inhibited by the coadministration of the $\gamma$-glutamyl transpeptidase inhibitor acivicin also failed to engender evidence for the formation of such conjugates (unpublished result). These results suggest that GSH conjugates of quercetin are not formed in the rat in vivo at levels detectable by the HPLC method employing UV and MS detection as described here. We cannot exclude the possibility that more sensitive detection methods such as electrochemical ones (Carvalho et al, 2004) may have led to quercetin GSH conjugate identification.

\section{Effect of quercetin metabolites on cellular PGE-2 production}

Human-derived HCA-7 colon cancer cells contain significant levels of COX protein, which has been shown to be almost exclusively COX-2 (Sharma et al, 2001). Therefore, measurement of PGE-2 in the cellular supernatant reflects predominantly COX-2 levels and activity. Cells were incubated for $6 \mathrm{~h}$ with quercetin or with selected glycosides and metabolites, and PGE-2 levels were determined. The $\mathrm{IC}_{50}$ for inhibition of PGE-2 production by quercetin was found to be $10 \mu \mathrm{M}$, and at $1 \mu \mathrm{M}$ quercetin reduced PGE-2 levels by $30 \%$ (result not shown). The quercetin progenitor glycoside rutin and the four quercetin metabolites isorhamnetin, tamarixetin, quercetin 3-O-sulphate and quercetin 7-O-sulphate were compared with quercetin in terms of their ability to inhibit PGE-2 production (Figure 6). Cells were incubated with agents at $10 \mu \mathrm{m}$. While rutin, quercetin 3-O-sulphate and quercetin 7-Osulphate failed to affect PGE-2 levels, both isorhamnetin and tamarixetin decreased PGE-2 levels by more than $90 \%$. It is important to point out that the COX-inhibitory activity of quercetin glucuronides, major quercetin metabolites in rats (Day et al, 2001), was not explored.

\section{DISCUSSION}

The results described above allow the following four conclusions to be drawn as to the metabolism of quercetin when administered as authentic aglycone: (i) in the rat, quercetin undergoes metabolic methylation and multiple conjugation reactions with activated sulphate and glucuronide, and metabolically generated isorhamnetin is also subject to such secondary conjugation reactions; (ii) methylated and sulphated species are metabolites of quercetin in humans; (iii) while quercetin can be oxidised to species that undergo reaction with GSH under in vitro conditions, such species seem not to be generated at detectable levels in rats in vivo; (i.v.) 


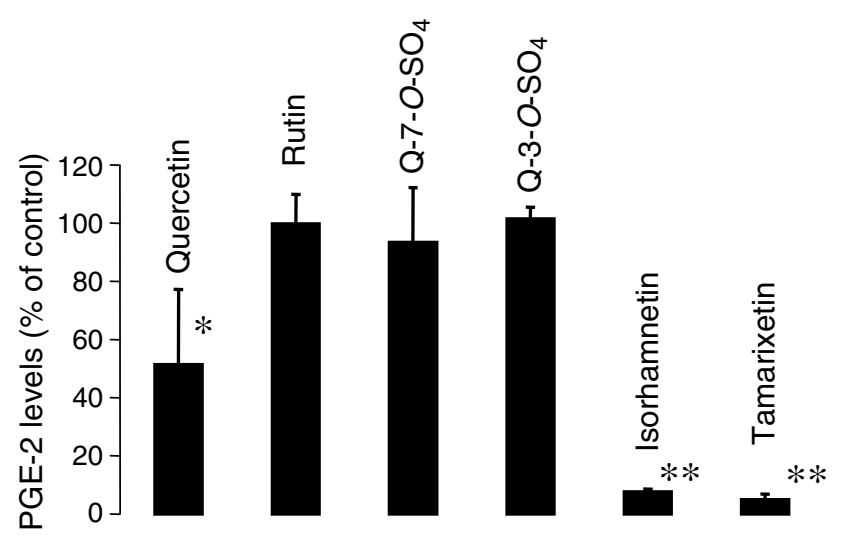

Figure 6 Effect of quercetin, rutin quercetin-7-O-sulphate $\left(\mathrm{Q}-7-\mathrm{O}_{-} \mathrm{SO}_{4}\right)$, quercetin-3-O-sulphate $\left(\mathrm{Q}-3-\mathrm{O}-\mathrm{SO}_{4}\right)$, isorhamnetin and tamarixetin (each $10 \mu \mathrm{M}$ ) on COX-2 enzyme activity, as reflected by PGE-2 levels, in cultures of HCA-7 colon cancer cells. The COX complement of HCA-7 cells is made up almost exclusively of COX-2, while COX-I is present only to a minor extent (Sharma et al, 200 I). Cells were incubated with agents for $6 \mathrm{~h}$, and PGE-2 levels were measured by ELISA. Asterisks indicate that values were significantly different from controls $(* P<0.01$, $* * P<0.001)$. For details of incubation conditions and measurement see Materials and Methods. The values are the mean \pm s.d. of three to five separate experiments, each conducted in triplicate.

metabolic methylation of quercetin confers potent COX-inhibitory properties onto the flavone molecule.

The pattern of conjugates generated in the rat as established here via scrupulous metabolite characterisation by MS is in broad agreement with previous reports in the literature on the biotransformation of quercetin after oral administration either as dietary glycoside or genuine aglycone (Ueno et al, 1983; Manach et al, 1997; Piskula and Terao, 1998). Only one methylated species, isorhamnetin ( $3^{\prime}-O$-methyl quercetin), was identified here, while its 4'-isomer, tamarixetin, was not. Tamarixetin was found previously in the plasma of rats, but only when they had received a flavonol-free diet prior to quercetin (Manach et al, 1997), which is consistent with its absence in the plasma of the rats studied here. Prior to our study, conjugates of quercetin had not been described in humans following the i.v. administration of pure quercetin. While in the work described here metabolism data were obtained from one human only, the results clearly hint at the possibility that quercetin undergoes metabolic sulphation and methylation not only in rodents but also in humans. Gross comparison of the doses and plasma levels suggests that the plasma levels achieved in rats immediately after i.v. injection resemble the levels achieved in the clinical trial of quercetin in humans (Ferry et al, 1996). The quercetin dose used in rats here in terms of body surface area (Freireich et al, 1966) was $40.6 \mathrm{mg} \mathrm{m}^{-2}\left(6.25 \mathrm{mg} \mathrm{kg}^{-1}\right)$, approximately $4.5 \%$ of the dose given to humans $\left(945 \mathrm{mg} \mathrm{m}^{-2}\right)$. In analogy, the plasma level $(14 \mu \mathrm{M})$ achieved in rats $5 \mathrm{~min}$ after quercetin administration was approximately $5 \%$ of that found in humans immediately after quercetin administration, which was $280 \mu \mathrm{m}$ (Ferry et al, 1996).

In the pharmacokinetic phase I study in cancer patients, quercetin was well tolerated (Ferry et al, 1996), and there was evidence of pharmacodynamic activity as indicated by inhibition of epidermal growth factor receptor phosphorylation, yet indications of nephrotoxicity were also observed. Overall, the study led to the conclusion that poor bioavailability mitigates against the potential of quercetin as a clinically viable therapeutic agent. The multiple conjugation reactions that quercetin has been shown to undergo in the work described here and previously, leading to methylated, sulphated and glucuronidated flavones, may be responsible for, or contribute to, its poor systemic availability. Significantly, such conjugative metabolism does not seem to include reaction with $\mathrm{GSH}$, thus rendering the possibility unlikely that GSH conjugates of quercetin are causally implicated in its putative nephrotoxic potential. In addition, there is no consistent conclusion to the effect of quercetin on cellular GSH levels by quercetin (Nijhoff et al, 1993, CanivencLavier et al, 1996; Sahu and Gray, 1996).

The two methylated congeners of quercetin, isorhamnetin and tamarixetin displayed potent COX enzyme inhibition, and their inhibitory potency was significantly higher than that of the parent molecule, quercetin. The $\mathrm{IC}_{50}$ for COX enzyme inhibition of quercetin has been reported to be $16 \mu \mathrm{m}$ (Formica and Regelson, 1995), and in the experimental design employed here using HCA-7 cells, it was approximately $10 \mu \mathrm{M}$. The nature of the COXinhibitory activity of the two metabolites and its relative specificity for COX-2 necessitates further investigation, as this observation may have clinical implications. That the methylated metabolites may conceivably play a pharmacodynamic role in the mammalian organism is borne out by a preliminary unpublished analysis of quercetin conjugates in bile conducted in our laboratory, according to which a major portion of drug-derived species generated in the rat organism was isorhamnetin.

The poor bioavailability of quercetin in the phase I clinical evaluation (Ferry et al, 1996) led to the conclusion that administration of quercetin may fail to furnish levels of bioactive species sufficient to exert useful pharmacological activity. This conclusion appears premature in the light of the fact that quercetin undergoes avid metabolism in species that may possess pharmacological activity, as hinted by our finding that isorhamnetin and tamarixetin are potent COX-2 inhibitors, at least in cells in vitro. Consistent with the notion that quercetin metabolites may be partially responsible for the pharmacological activity of the parent flavonol, quercetin conjugates have previously been found to retain, at least in part, the abilities of the parent molecule to exert antioxidation (Da Silva et al, 1998; Manach et al, 1998) and to inhibit xanthine oxidase and lipoxygenase (Day et al, 2000). Furthermore, products of the metabolic fission of quercetin have been shown to demonstrate greater antioxidant potency than their precursor (Merfort et al, 1996).

From the mechanistic standpoint, quercetin is a multitargeted agent and has poor bioavailability in the mammalian organism, and it shares these properties with many diet-derived polyphenols. The results outlined here support the supposition that metabolites of quercetin may be involved in its bioactivity, a suggestion that warrants further study designed to unravel the full potential of this molecule in the prevention or treatment of disease.

\section{ACKNOWLEDGEMENTS}

This work was supported by an MRC programme grant. We acknowledge the kind gift of HCA-7 cells from Dr S Kirkland (Hammersmith Hospital, Imperial College, London, UK) and thank Ms C Winfield for help with the drafting of this manuscript and Dr M Gaskell for proofreading.

\section{REFERENCES}

Ader P, Wessmann A, Wolffram S (2000) Bioavailability and metabolism of the flavonol quercetin in the pig. Free Radic Biol Med 28: $1056-1067$
Awad HM, Boersma MG, Boeren S, van Bladeren PJ, Vervoort J, Rietjens IMCM (2001) Structure-activity study on the quinone/quinone methide chemistry of flavonoids. Chem Res Toxicol 14: 398-408 
Awad HM, Boersma MG, Vervoort J, Rietjens IMCM (2000) Peroxidasecatalyzed formation of quercetin quinone methide-glutathione adducts. Arch Biochem Biophys 378: 224-233

Boersma MG, Vervoort J, Szymusiak H, Lemanska K, Tyrakowska B, Cenas N, Segura-Aguilar J, Rietjens IMCM (2000) Regioselectivity and reversibility of the glutathione conjugation of quercetin quinone methide. Chem Res Toxicol 13: 185-191

Booth AN, Murray CW, Jones FT, DeEds F (1956) Metabolic fate of rutin and quercetin in the animal body. J Biol Chem 233: 251-257

Butterworth M, Lau SS, Monks TJ (1997) Formation of catechol estrogen glutathione conjugates and gamma-glutamyl transpeptidase-dependent nephrotoxicity of 17 beta-estradiol in the golden Syrian hamster. Carcinogenesis 18: $561-567$

CanivencLavier MC, Vernevaut MF, Totis M, Siess MH, Magdalou J, Suschetet M (1996) Comparative effects of flavonoids and model inducers on drug-metabolizing enzymes in rat liver. Toxicology 114: $19-27$

Carvalho M, Milhazes N, Remiao F, Borges F, Fernandes E, Amado F, Monks TJ, Carvalho F, Bastos ML (2004) Hepatotoxicity of 3,4methylenedioxyamphetamine and alpha-methyldopamine in isolated rat hepatocytes: formation of glutathione conjugates. Arch Toxicol 78: $16-24$

Da Silva EL, Piskula MK, Yamamoto N, Moon JH, Terao J (1998) Quercetin metabolites inhibit copper ion-induced lipid peroxidation in rat plasma. FEBS Let 430: 405-408

Day AJ, Bao, YP, Morgan MRA, Williamson G (2000) Conjugation position of quercetin glucuronides and effect on biological activity. Free Radic Biol Med 29: $1234-1243$

Day AJ, Mellon F, Barron D, Sarrazin G, Morgan MRA, Williamson G (2001) Human metabolism of dietary flavonoids: identification of plasma metabolites of quercetin. Free Radic Res 35: 941 -952

Douglass CD, Hogan R (1958) Formation of protocatechuic acid from quercetin by rat kidney in vitro. J Biol Chem 230: 625-629

Dunnick JK, Hailey JR (1992) Toxicity and carcinogenicity studies of quercetin, a natural component of foods. Fund Appl Toxicol 19: 423-431

Duckworth HW, Coleman JE (1970) Physiochemical and kinetic properties of mushroom tyrosinase. J Biol Chem 245: 1613-1625

Ferry DR, Smith A, Malkhandi J, Pyfe DW, deTakats PG, Anderson D, Baker J, Kerr DJ (1996) Phase I clinical trial of the flavonoid quercetin: pharmacokinetics and evidence for in vivo tyrosine kinase inhibition. Clin Cancer Res 2: 659-668

Formica JV, Regelson W (1995) Review of the biology of quercetin and related bioflavonoids. Food Chem Toxicol 33: $1061-1080$

Freireich EJ, Gehan EA, Rall DP, Schmidt LH, Skipper HE (1966) Quantitative comparison of toxicity of anticancer agents in mouse, rat, hamster, dog, monkey, and man. Cancer Chemother Rep 50: 219-244

Galati G, Moridani MY, Chan TS, O'Brien PJ (2001) Peroxidative metabolism of apigenin and naringenin $v s$ luteolin and quercetin: glutathione oxidation and conjugation. Free Radic Biol Med 30: 370-382

Gescher AJ, Steward WP (2003) Commentary: relationship between mechanisms, bioavailibility and preclinical chemopreventive efficacy of resveratrol: a conundrum. Cancer Epidemiol Biomarkers Prev 12: 953 - 957

Gugler R, Leschik M, Dengler HJ (1975) Disposition of quercetin in man after single oral and intravenous doses. Eur J Clin Pharmacol 9: 229-234

Hertog MGL, Hollman PCH, Katan MB (1992) Content of potentially anticarcinogenic flavonoids of 28 vegetables and 9 fruits commonly consumed in the Netherlands. J Agr Food Chem 40: 2379-2383

Hertog MGL, Feskens EJM, Hollman PCH, Katan MB, Kromhout D (1993) Dietary antioxidant flavonoids and risk of coronary heart disease - the Zutphen elderly study. Lancet 342: 1007-1011

Hertog MGL, Feskens EJM, Hollman PCH, Katan MB, Kromhout D (1994) Dietary flavonoids and cancer risk in the Zutphen elderly study. Nutr Cancer 22: 175 - 184

Hertog MGL, Kromhout D, Aravanis C, Blackburn H, Buzina R, Fidanza F, Giampaoli S, Jansen A, Menotti A, Nedeljkovic S, Pekkarinen M, Simic BS, Toshima H, Feskens EJM, Hollman PCH, Katan MB (1995) Flavonoid intake and long-term risk of coronary-heart-disease and cancer in the seven countries study. Arch Intern Med 155: 381-386
Hertog MGL, Hollman PCH (1996) Potential health-effects of the dietary flavonol quercetin. Eur J Clin Nutr 50: 63-71

Hollman PCH, Katan MB (1997) Absorption, metabolism and health effects of dietary flavonoids in man. Biomed Pharmacother 51: 305-310

Iverson SL, Shen L, Anlar N, Bolton JL (1996) Bioactivation of estrone and its catechol metabolites to quinoid-glutathione conjugates in rat liver microsomes. Chem Res Toxicol 9: 492-499

Jones DJL, Lim CK, Ferry DR, Gescher A (1998) Determination of quercetin in human plasma by HPLC with spectrophotometric or electrochemical detection. Biomed Chromatogr 12: $232-235$

Keli SO, Hertog MGL, Feskens EJM, Kromhout D (1996) Dietary flavonoids, antioxidant vitamins, and incidence of stroke - the Zutphen study. Arch Intern Med 156: 637-642

Le Marchand L, Murphy SP, Hankin JH, Wilkens LR, Kolonel LN (2000) Intake of flavonoids and lung cancer. J Natl Cancer Inst 92: 154-160

MacGregor JT, Jurd L (1978) Mutagenicity of plant flavonoids: Structural requirements for mutagenic activity in Salmonella typhimurium. Mutat Res 54: $297-309$

Manach C, Morand C, Demigne C, Texier O, Regerat F, Remesy C (1997) Bioavailability of rutin and quercetin in rats. FEBS Lett 409: $12-16$

Manach C, Morand C, Crespy V, Demigne C, Texier O, Regerat F, Remesy C (1998) Quercetin is recovered in human plasma as conjugated derivatives which retain antioxidant properties. FEBS Lett 426: $331-336$

Marnett LJ, DuBois RN (2002) COX-2: a target for colon cancer prevention. Annu Rev Pharmacol Toxicol 42: 55-80

Merfort I, Heilmann J, Weiss M, Pietta P, Gardana C (1996) Radical scavenger activity of 3 flavonoid metabolites studied by inhibition of chemiluminescence in human PMNs. Planta Med 62: 289-292

Monks TJ, Lau SS, Highet RJ, Gillette JR (1985) Glutathione conjugates of 2bromohydroquinone are nephrotoxic. Drug Metab Dispos 13: 553-559

Mutoh H, Takahashi M, Fukuda K, Komatsu H, Enya T, MatsushimaHibiya Y, Sugimura T, Wakabayashi K (2000) Suppression by flavonoids of cyclooxygenase-2 promoter-dependent transcriptional activity in colon cancer cells: structure-activity relationship. Jpn J Cancer Res 91: 686-691

Nijhoff W, Groen AGM, Peters WHM (1993) Induction of rat hepatic and intestinal glutathione $S$-transferases and glutathione by dietary naturallyoccurring anticarcinogens. Int J Oncol 3: 1131-1139

Nijveldt RJ, van Nood E, van Hoorn DEC, Boelens PG, van Norren K, van Leeuwen PAM (2001) Flavonoids: a review of probable mechanisms of action and potential applications. Am J Clin Nutr 74: 418-425

Peters MMCG, Jones TW, Monks TJ, Lau SS (1997) Cytotoxicity and cellproliferation induced by the nephrocarcinogen hydroquinone and its nephrotoxic metabolite 2,3,5-(tris-glutathion-S-yl)hydroquinone. Carcinogenesis 18: $2393-2401$

Petrakis PL, Kallianos AG, Wender SH, Shetlar MR (1959) Metabolic studies of quercetin labeled with C14. Arch Biochem Biophys 85: 264-271

Piskula MK, Terao J (1998) Quercetin's solubility affects its accumulation in rat plasma after oral administration. J Agric Food Chem 46: 4313-4317

Raso GM, Meli R, Di Carlo G, Pacilio M, Di Carlo R (2001) Inhibition of inducible nitric oxide synthase and cyclooxygenase-2 expression by flavonoids in macrophage J774A.1. Life Sci 68: 921-931

Sahu SC, Gray GC (1996) Prooxidant activity of flavonoids - effects on glutathione and glutathione-S-transferase in isolated rat-liver nuclei. Cancer Lett 104: 193 - 196

Shali NA, Curtis CG, Powell GM, Roy AB (1991) Sulphation of the flavonoids quercetin and catechin by rat-liver. Xenobiotica 21: $881-893$ Sharma RA, Gescher AJ, Plastaras JP, Leuratti C, Singh R, Gallacher-Horley B, Offord E, Marnett LJ, Steward WP, Plummer SM (2001) Cyclooxygenase-2 activity, malondialdehyde and pyrimidopurinone adducts of deoxyguanosine in human colon cells. Carcinogenesis 22: 1557-1560

Ueno I, Nakano N, Hirono I (1983) Metabolic-fate of [C-14] quercetin in the $\mathrm{ACl}$ rat. Jpn J Exp Med 53: 41-50

Workman P, Twentyman P, Balkwill F, Balmain A, Chaplin D, Double J, Embleton J, Newell D, Raymond R, Stables, J Stephens T, Wallace J (1998) United Kingdom Co-ordinating Committee on Cancer Research (UKCCCR) Guidelines for the Welfare of Animals in Experimental Neoplasia (Second Edition). Br J Cancer 77: 1-10 